\title{
Evaluation of wind power for electrical energy generation in the mediterranean coast of Palestine for 14 years
}

\author{
Ahmed Badawi', Nurul Fadzlin Hasbullaha², Siti Yusoff ${ }^{3}$, Sheroz Khan ${ }^{4}$, Aisha Hashim ${ }^{5}$, \\ Alhareth Zyoud ${ }^{6}$, Mohammed Elamassie ${ }^{7}$ \\ 1,2,3,4,5,6 Department of Electrical and Computer Engineering, International Islamic University, Malaysia \\ ${ }^{7}$ Department of Electrical and Electronics Engineering, Özyeğin University, Turkey
}

\section{Article Info}

Article history:

Received Jun 16, 2018

Revised Jan 2, 2019

Accepted Mar 4, 2019

\section{Keywords:}

Mean wind speed

Potential energy

Wind energy

\begin{abstract}
The generation, distributionand transmission of electricity in Palestine have recently emerged as major issues. This study comprehensively assesses the production of wind energy and the estimation of wind energy potential in Palestine's south coastal plain. The goal is to evaluate Palestine's wind energy production by studying wind data and calculating energy and power. This study analyses two actual time series datasets. Findings are elaborated to determine the wind energy conversion per $1 \mathrm{~m}^{2}$. The wind speed data from January 1996 to December 2006 in Gaza and from January 2012 to December 2015 in Ashqelon are selected as the data sample. This study is crucial given the need for clean and renewable energy, the power shortage in the Gaza Strip and the limited number of wind energy studies conducted in the south coastal plain of Palestine, especially Gaza Strip. This study estimates the wind energy potential of the Gaza Strip to determine the wind potential. The annual mean wind speed and power are $4.11 \mathrm{~ms}^{-1}$ and 903.4 $\mathrm{Wm}^{-2}$, respectively. Moreover, the study clarifies the electrical energy generation in the Gaza Strip using small-scale turbines and offers a feasible alternative to existing schemes.
\end{abstract}

Copyright $\left({ }_{0} 2019\right.$ Institute of Advanced Engineering and Science. All rights reserved.

\section{Corresponding Author:}

Siti Yusoff,

Department of Electrical and Computer Engineering,

International Islamic University,

St. Gombak, 53100 Selangor, Malaysia.

Email: sitiyusoff@iium.edu.my

\section{INTRODUCTION}

The global demand for and consumption of energy have rapidly increased as a result of the increased housing scheme brought about by rapid population growth. Many countries have exerted effort to use renewable energy to address these crises. Wind energy is one of the most commonly used renewable energy resource. Recent research on wind power technology has become increasingly significant at the global scale [1-4].

The nameplate capacity of wind power generation worldwide was approximately $539 \mathrm{GW}$ at the end of 2017 [5]. Wind energy has shown great prospect in water pumping and electricity generation applications. Wind energy use depends on the means and variety of wind speeds in a given area [6, 7]. The installed global wind capacity from 2001 to 2017 is shown in Figure 1.

Palestine lacks the traditional resources for stable electrical energy. It has witnessed a rise in the gradual reduction of non-renewable sources given the challenges brought about by siege, terror, war and vandalism. Alternative sources of energy (e.g. wind power) have thus become increasingly necessary due to the state's continued disruption of fuel and electric power $[8,9]$. 


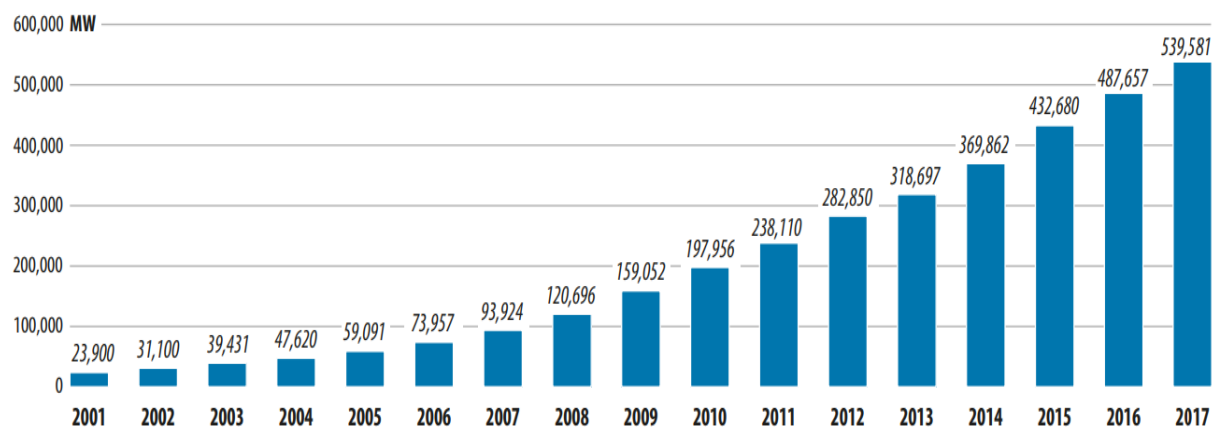

Figure 1. Global cumulative installed wind capacity in 2001-2017 [5]

This study assesses wind energy production in Palestine by examining wind data through energy and power calculation. Several studies have been conducted indifferent territories across Palestine, but we believe that the present study is the first research study conducted in Gaza. Calculating wind power density (WPD) based on the measured data of a target meteorological location is the best strategy to investigate the feasibility of using wind energy at any location [10, 7, 11-13].

The information used in this study is obtained from the coastal cities of Ashqelon (January 2012December 2015), Gaza and Khan Yunis (January 1996-December 2006). The three cities have similar climate [8]. This study is based on Gaza's wind data collected by the Palestinian Central Bureau of Statistics, which has been operating since 2007. The wind industry must describe wind speed variations which are important in optimising wind turbine design and minimising energy generation costs. This study approximates the potential of wind energy in the south coastal plain of Palestine. It also discusses how varying wind speeds can support the optimisation ofwind energy turbine designs to generate cost-effective wind energy.

\section{ESTIMATION OF WIND POWER DENSITY (WPD)}

WPD reflects a target location's wind energy resource capacity [14]. WPD is measured on the basis of the 1) available power specified by the measured mean wind speed (MWS) of the meteorological station and 2) frequency distribution function (two-parameterWeibull method) [2, 15, 4, 16]. WPD is an essential indicator to understandthe potential of wind resources. It also represents the amount of wind energy at different wind speeds in a particular location. The knowledge of WPD can enrich our knowledge of wind turbine performance and aid in the selection of optimum wind turbines. WPD identifies a location's accessible energy level. It is calculated in two ways: based on measured wind speed data and proper distribution function. This study calculates available power on the basis of actual wind speeds. Estimation is performed to predict a) power generation among a grid of wind turbines and (b) future power generation inagiven site.

\subsection{Statistical analysis of measured wind data}

Supposea wind speed of $v\left(\mathrm{~ms}^{-1}\right)$. Wind power is proportional to the cube of wind speed and can be computed as follows [14, 17]:

$$
P(V)=\frac{1}{2} \rho U_{\text {avg }}^{3},
$$

Where $\rho$ is the air density for normal environmental conditions. For example, at sea level, the temperature is $15^{\circ}$, one atmospheric pressure $(14.7 \mathrm{psi})$, and the atmosphere is $1.225 \mathrm{kgm}^{-3}$. Thus, the power density for the actual time series wind speed data can be calculated with [14, 17].

$$
\bar{P}=\frac{1}{2 n} \rho \sum_{i=1}^{n} v^{3}=\frac{1}{2} \rho A\left(\overline{v^{3}}\right)
$$

Where $\mathrm{n}$ is the volume of data, $\rho$ is the air density and $v$ is the wind speed $\left(\mathrm{ms}^{-1}\right)$ in the specified period of time $[14,17]$. 


\subsection{Turbine power output}

The wind turbine generator's power output is expressed in (1). Figure 2 presents the relationship between power and wind speed. It illustrates the size of the electrical power output for the turbine at different wind speeds. The wind turbine's power curve exhibits this relationship between the rated capacity and cut-in wind speed (the speed at which the wind turbine starts to operate). The wind turbine reaches its rated capacity at a wind speed of $12 \mathrm{~ms}^{-1}$ to $16 \mathrm{~ms}^{-1}$ depending on individual wind turbine design.

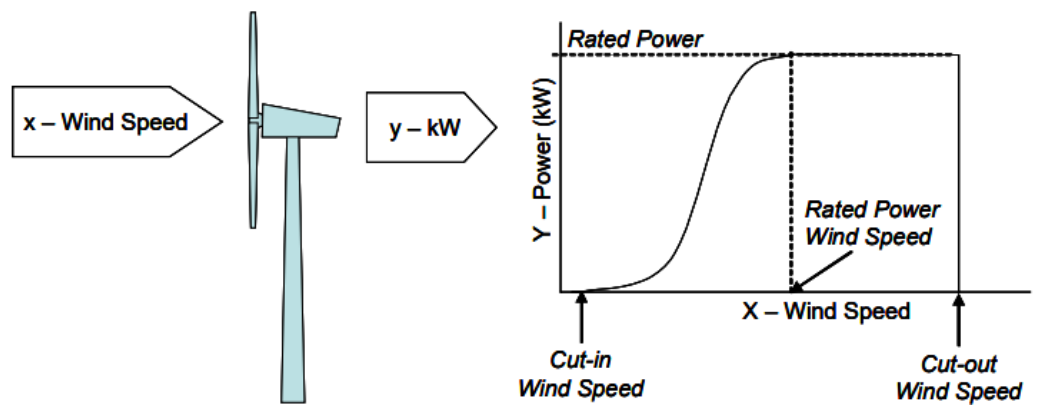

Figure 2. Relationship between wind speed and output [18]

\subsection{Max power output $v_{r}$}

Max power outpute quates to rated turbine power. This constant power output is sustained above the rated wind speed.

\subsection{Cut-in wind speed $v_{c}$}

Cut-in wind speed is the wind speed at which the wind turbine is intended to start running.

\subsection{Cut-out wind speed $v_{f}$}

Damage to the turbine or its surroundings is avoided by stopping the wind turbine at high wind speeds (e.g. $25 \mathrm{~ms}^{-1}$ ). The stop wind speed is called the cut-out wind speed.

$$
P e=\left\{\begin{array}{lr}
0 & \left(v<v_{c}\right) \\
P_{e R} \frac{v^{k}-v_{c}{ }^{k}}{v_{R}{ }^{k}-v_{c}{ }^{k}} & \left(v_{c} \leq v \leq v_{R}\right) \\
P_{e R} & \left(v_{R} \leq v \leq v_{F}\right) \\
0 & \left(v>v_{F}\right),
\end{array}\right.
$$

Where $\mathrm{P}_{\mathrm{eR}}$ is the rated electrical power, $v_{c}$ is the cut-in wind speed, $v_{R}$ is the rated wind speed and $v_{F}$ is the cut-out speed of the model wind turbine.

\subsection{Wind potential energy} function.

The theoretical wind energy per unit area for a given period $\mathrm{T}$ is based on the Weibull probability

$$
E_{w}=\frac{1}{2} \rho C^{3} \Gamma\left(1+\frac{3}{k}\right) T
$$

Where $\rho$ is the air density.

The following equation obtains similar energy on the basis ofactual time-series data.

$$
E_{a}=\frac{1}{2} \rho v^{3} T
$$

Where $v$ is the mean of the cubed wind speed [19]. $v_{\mathrm{E} \max }$ is the wind speed that carries the maximum wind energy, and the most probable wind speed $v_{\mathrm{mp}}$ is the modal wind speed for the given wind distribution $[20,21]$. 


$$
\begin{aligned}
& \bigcup_{E \max }=c\left(\frac{k+2}{k}\right)^{\frac{1}{k}} \\
& \bigcup_{m p}=c\left(\frac{k-1}{k}\right)^{\frac{1}{k}}
\end{aligned}
$$

\section{WIND SPEED FOR COASTAL PLAIN IN PALESTINE AS A CASE STUDY}

Palestine is situated between the Jordan River and the Mediterranean Sea in Western Asia. It is surrounded by Lebanon in the north, Jordan and Syria in the east, the Mediterranean Sea in the west and Egypt and the Gulf of Aqaba inthe south Figure 3. This study focuses on the southern coastal plain of Palestine, facing the Mediterranean Sea. The coastal area's climate is warm and rainy in autumn and hot and dry in summer. Wind speed in this area is generally below $15 \mathrm{~ms}^{-1}$, and strong wind speed does not exceed $25 \mathrm{~ms}^{-1}$.

Figure 4 shows the three locations for data collection. Wind speeds in Gaza and Khan Yunis were recorded from January 1996 to December 2005. Wind speed in Ashqelon was recorded from January 2012 to December 2015. Gaza, Khan Yunis and Ashqelon have the same weather as coastal cities.

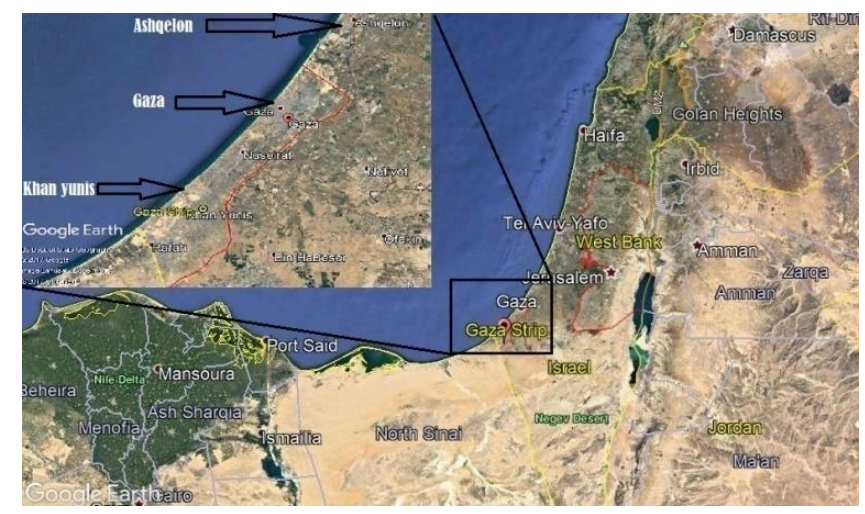

Figure 4. South coastal plain of Palestine [22]

Figure 5 shows the changes in the actual MWS between 1996 and 2006 in Palestine's south coastal plain. The pie charts show that MWS at $5 \mathrm{~ms}^{-1}$ is slightly below $40 \%$ of the total and covers approximately 140 days of the total. The MWS between 7 and $15 \mathrm{~ms}^{-1}$ is $30 \%$ of the total and covers approximately 110 days. Exactly $30 \%$ of the total wind speed was between 7 and $15 \mathrm{~ms}^{-1}$ and is the rated wind speed to generate electricity. It is the rated power on a small scale. MWS in the coastal area at above $15 \mathrm{~ms}^{-1}$ is just over $20 \%$ of the total wind speed the highest MWS in winter is $25 \mathrm{~ms}^{-1}$.



Figure 5. Actual MWS percentage in Gaza for 10 years [18], [23] 
Figure 6 shows the percentage of the monthly MWS in Ashqelon between 2012 and 2015. The graph shows a dramatic decrease in the MWS from February to April2012, reaching an all-time low of $3.2 \mathrm{~ms}^{-1}$. MWS reached approximately $5 \mathrm{~ms}^{-1}$ in the month of January. MWS then steadily increasedand reached approximately $4 \mathrm{~ms}^{-1}$. However, the curve shows a downward movement during the last three months. MWS significantly increased, reaching approximately $4.7 \mathrm{~ms}^{-1}$ in April 2013. The curve fluctuated during the last eight months of 2013. MWS significantly increased from January to August 2014, reaching $4.8 \mathrm{~ms}^{-1}$ before it dropped in the last four months of the year. MWS jumped to $5.1 \mathrm{~ms}^{-1}$ in January 2015, fluctuated and then reached its peak point in June. However, MWS gradually declined to an all-time low of $3 \mathrm{~ms}^{-1}$ between July and December of the same year. MWS changed between $3 \mathrm{~ms}^{-1}$ and $5 \mathrm{~ms}^{-1}$ during this period [24].

The average MWS is approximately $4.11 \mathrm{~ms}^{-1}$ for the four years covered in the study. MWS records show that wind speed in the coastal plain is affected and results in the down sizing of electricity generation on a large scale and in challenges in power production. The large-scale wind turbine's cut-in wind speed is equal to at least $9 \mathrm{~ms}^{-1}$. Nevertheless, wind generation is presently possible on a small scale.

Figure 7 presents the maximum wind speed, which ranged from $8 \mathrm{~ms}^{-1}$ to $16 \mathrm{~ms}^{-1}$ between 2012 and 2015. The maximum wind speed sufficiently produces power from wind turbines. The maximum wind speeds for 2012, 2013, 2014 and 2015 are 8.54, 7.98, 7.87 and $8.47 \mathrm{~ms}^{-1}$, respectively. Table 1 shows the standard deviation for four years.

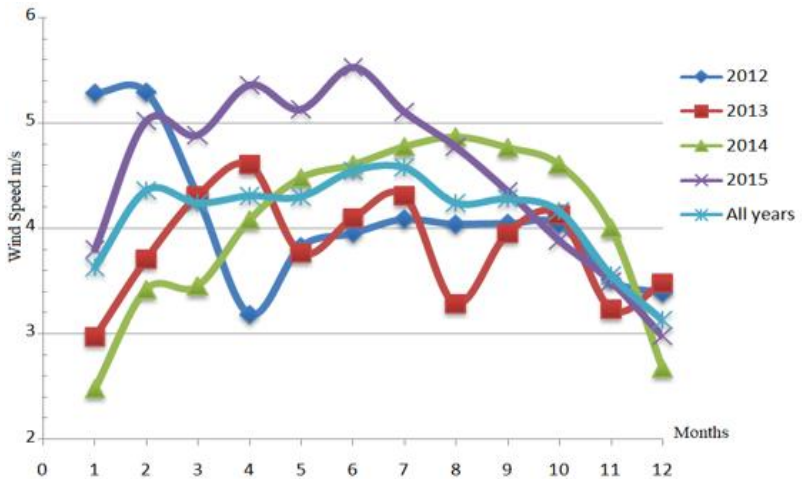

Figure 6. MWS in Ashqelon from January 2012 to December 2015 [24]

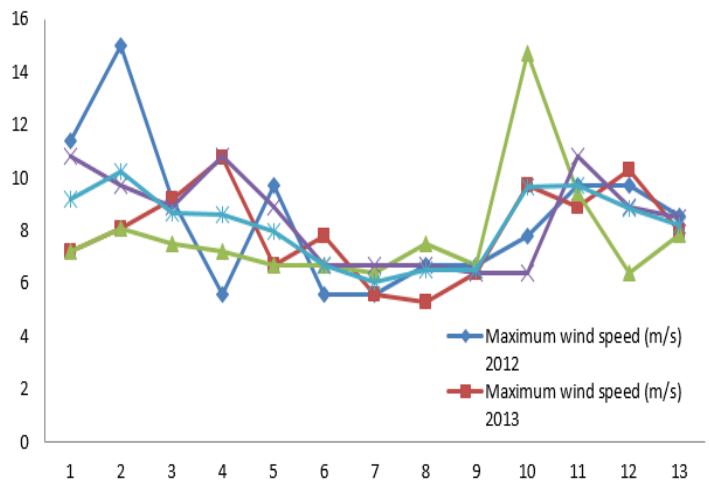

Figure 7. Maximum wind speed for Ashqelon from 2012 to 2015

Table 1. Actual maximum wind speed records and standard deviation

\begin{tabular}{cccccc}
\hline Period & \multicolumn{4}{c}{ Standard deviation $\left(\mathrm{ms}^{-1}\right)$} & \\
Years/Months & 2012 & 2013 & 2014 & 2015 & All years \\
\hline Jan & 2.1771 & 2.0640 & 1.8853 & 2.1771 & 2.075875 \\
Feb & 3.0578 & 2.1333 & 1.8962 & 3.0578 & 2.536275 \\
Mar & 2.3936 & 2.4573 & 1.6586 & 2.3936 & 2.225775 \\
Apr & 1.9926 & 2.5309 & 1.6637 & 1.9926 & 2.04495 \\
May & 1.5874 & 1.6633 & 1.5726 & 1.5874 & 1.602675 \\
Jun & 0.9266 & 1.4895 & 1.2879 & 0.9266 & 1.157650 \\
Jul & 0.8507 & 1.4895 & 0.8884 & 0.8507 & 1.019825 \\
Aug & 0.8679 & 0.9103 & 1.0827 & 0.8679 & 0.932200 \\
Sep & 0.9208 & 1.1550 & 1.2658 & 0.9208 & 1.065600 \\
Oct & 1.3264 & 1.7579 & 2.3828 & 1.3264 & 1.698375 \\
Nov & 2.5956 & 2.0104 & 2.8651 & 2.5956 & 2.516675 \\
Dec & 1.9752 & 2.5305 & 1.6046 & 1.9752 & 2.021375 \\
Mean & 1.9873 & 1.9179 & 1.8993 & 1.9873 & 1.741438 \\
\hline
\end{tabular}

\section{POWER AND ENERGY ESTIMATION}

The (1) calculates the actual wind power, the maximum amount of power for MWS in 2015 was approximately $1084 \mathrm{Wm}^{-2}$ because of the highest MWS in that year. The total wind power levels for 2012, 2013, 2014 and 2015 are 977, 744, 808 and $1084 \mathrm{Wm}^{-2}$, respectively. 
In Figure 8 Wind energy levels for 2012, 2013, 2014 and 2015 are 23.45, 17.86, 19.40 and 26.02 $\mathrm{KWm}^{-2}$, respectively. In Figure 9 the wind energy levels evaluated are $52771.12 \mathrm{kWm}^{-2}$ for 2012, 36083.19 $\mathrm{kWm}^{-2}$ for $2013,40087.51 \mathrm{kWm}^{-2}$ for 2014 and $43726.76 \mathrm{kWm}^{-2}$ for 2015.

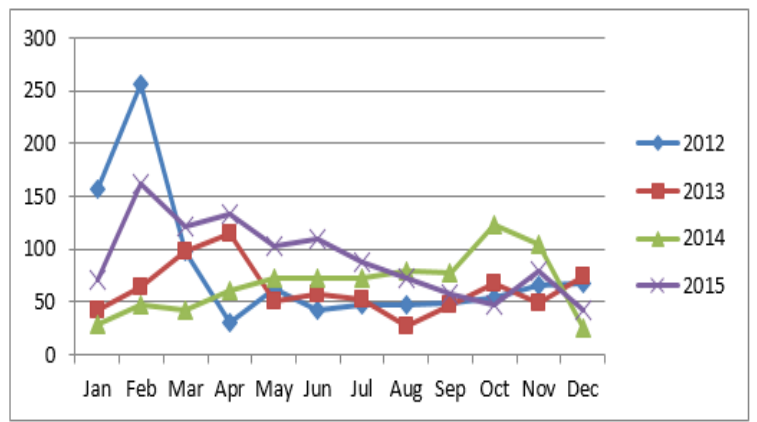

Figure 8. Wind Energy (KWm-2h) for mean wind speed between 2012 and 2015

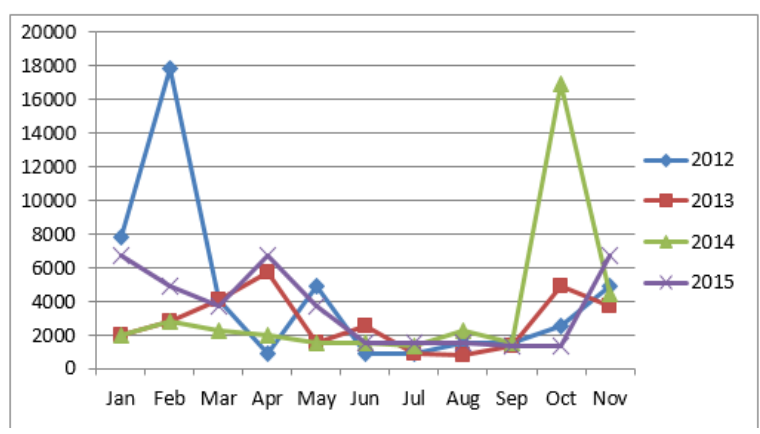

Figure 9. Wind Energy $\left(\mathrm{KWm}^{-2} \mathrm{~h}\right)$ for maximum wind speed between 2012 and 2015

Wind speed rapidly changes in any area. The relationship between energy and power is proportionate to the cube of wind speed. This study considers the maximum wind speed in energy and power evaluations. The actual wind power levels evaluated for the maximum wind speed are $6024.1 \mathrm{Wm}^{-2}$ in 2012 , $4119.1 \mathrm{Wm}^{-2}$ in $2013,4576.2 \mathrm{Wm}^{-2}$ in 2014 and $4991.6 \mathrm{Wm}^{-2}$ in 2015. The highest amount of wind energy was recorded in 2012 because of its highest wind speed value according to the MWS per month.

Table 2 presents that the annual wind speed carrying the maximum energy speed in 2015 was 4.53 $\mathrm{ms}^{-1}$ and thatthe maximum annual mean power density was $89.7332 \mathrm{Wm}^{-2}$. The annual MWS ranged from $3.82 \mathrm{~ms}^{-1}$ to $4.53 \mathrm{~ms}^{-1}$. The wind speed is appropriate for small-scale applications.

Table 2. Estimation of wind power and energy for maximum wind speed

\begin{tabular}{lccccc}
\hline Years & MWS ms & Standard divination $\sigma \mathrm{ms}^{-1}$ & Variation Coefficient $\%$ & Power density $\left(\mathrm{Wm}^{-2}\right)$ & $\mathrm{Energy} \mathrm{Wm}^{-2} \mathrm{~h}$ \\
\hline 2012 & 4.0800 & 1.9873 & 51.1173 & 80.3672 & $7.04016 \mathrm{e}+5$ \\
2013 & 3.8200 & 1.9179 & 50.2685 & 62.0054 & $5.3870 \mathrm{e}+05$ \\
2014 & 4.0200 & 1.8993 & 47.2570 & 67.3838 & $5.9028 \mathrm{e}+05$ \\
2015 & 4.5300 & 1.9873 & 43.9606 & 89.7332 & $7.8606 \mathrm{e}+05$ \\
Average & 4.1125 & 1.94795 & 48.15085 & 74.8724 & 654764 \\
\hline
\end{tabular}

\section{CONCLUSION}

This study analysed wind speed data covering 14 years. The region's mean wind power shows that the location may not be suitable for grid-connected electricity production, although the site has adequate wind for wind power generation using wind turbines. This study is conducted to estimatethe wind energy potential of Gaza. The results should aid scientists and technocrats in choosing suitable locations for wind turbine generators. MWS, coefficient of variation andthe mean and maximum wind power are obtained on the basis ofactual measured data. This study finds thatthe use of commercial-scale wind power and its connection to the main electricity network are not possible. Nevertheless, the location is suitable for wind turbine installations at a small scale. Thus, wind energy generated for houses or organisations is a possible alternative resource. The calculated wind power source is low, but it can harness wind energy using small wind turbine generators. This study presents the initial step towards the feasible installation of wind turbines in Palestine.

\section{ACKNOWLEDGMENTS}

This work was partially supported by Ministry of Higher Education Malaysia (Kementerian Pendidikan Tinggi) under Fundamental Research Grant Scheme (FRGS) number FRGS17-038-0604.

\section{REFERENCES}

[1] Albatsh F. M., Mekhilef S., Ahmad S., Mokhlis H., and Hassan M., "Enhancing power transfer capability through flexible AC transmission system devices: a review," Frontiers of Information Technology \& Electronic Engineering, vol. 16, no. 8, pp. 658-678, 2015. 
[2] Albuhairi M. H., "Assessment and analysis of wind power density in Taiz-republic of Yemen," Ass. Univ. Bull. Environ. Res, vol. 9, no. 2, pp. 13-21, 2006.

[3] Costa Rocha P. A., de Sousa R. C., de Andrade C. F., and da Silva M. E. V., "Comparison of seven numerical methods for determining weibull parameters for wind energy generation in the northeast region of Brazil," Applied Energy, vol. 89, no. 1, pp. 395-400, 2012.

[4] Parajuli A., "A statistical analysis of wind speed and power density based on weibull and rayleigh models of Jumla, Nepal," Energy and Power Engineering, vol. 8, no. 7, pp. 271-282, 2016.

[5] FRIED, L., "Global Wind Statistics," Global Wind Energy Council (GWEC), 2017.

[6] Azad A. K., Rasul M. G., Islam R., and Shishir, I. R., "Analysis of wind energy prospect for power generation by three weibull distribution methods," Energy Procedia, vol. 75, pp. 722-727, 2015.

[7] Ismail B., Naain M. M., Alhamrouni I., Awalin L. J., Albatsh F., and Hamid, M. F. A., "Proposed location of grid connected wind-pv hybrid system based on load flow and voltage stability indices study," World Academy of Science, Engineering and Technology, International Journal of Electrical and Computer Engineering, vol. 3, no. 12, 2016.

[8] Badawi A. S. A., "An analytical study for establishment of wind farms in palestine to reach the optimum electrical energy," Masters Thesis of The Islamic University of Gaza, Palestine, 2013.

[9] GWEC, "Global wind statistics 2016", GWEC, 2017.

[10] Arslan T., Bulut Y. M., and Altın Yavuz A., "Comparative study of numerical methods for determining weibull parameters for wind energy potential," Renewable and Sustainable Energy Reviews, vol. 40, pp. 820-825, 2014.

[11] Badawi A. S. A. "Numerical Analysis for Determining the Weibull Parameters using Seven Techniques in the Mediterranean Coast of Palestine (Under Review)," renewable energy Elsevier at https://ees.elsevier.com/rene/default.asp, 2018a.

[12] Badawi, A. S. A. "Weibull Probability Distribution of Wind Speed for Gaza Strip for 10 Years," www.scientific.net, 2018b.

[13] Bilir L., İmir M., Devrim Y. and Albostan, A., "An investigation on wind energy potential and small scale wind turbine performance at İncek region-Ankara, Turkey," Energy Conversion and Management, vol. 103, pp. 910-923, 2015.

[14] Mohammadi K., Alavi O., Mostafaeipour A., Goudarzi N. and Jalilvand M., "Assessing different parameters estimation methods of weibull distribution to compute wind power density," Energy Conversion and Management, vol. 108, pp. 322-335, 2016.

[15] Carlin P. W., "Analytical expressions for maximum wind turbine average power in a rayleigh wind regime," National Renewable Energy Laboratory, 1996.

[16] Pishgar-Komleh S. H., Keyhani A., and Sefeedpari P., "Wind speed and power density analysis based on weibull and rayleigh distributions (a case study: Firouzkooh county of Iran)," Renewable and Sustainable Energy Reviews, vol. 42, pp. 313-322, 2015.

[17] Mohammadi K., and Mostafaeipour A., "Using different methods for comprehensive study of wind turbine utilization in Zarrineh, Iran," Energy Conversion and Management, vol. 65, pp. 463-470, 2013.

[18] Data Source, "Palestinian Energy and Natural Resources Authority," Gaza Strip, Palestine.

[19] Andrade C. F. d., Maia Neto H. F., Costa Rocha P. A., and Vieira da Silva M. E., "An efficiency comparison of numerical methods for determining weibull parameters for wind energy applications: A new approach applied to the northeast region of Brazil," Energy Conversion and Management, vol. 86, pp. 801-808, 2014.

[20] Akpinar E. K., and Akpinar S. "An assessment on seasonal analysis of wind energy characteristics and wind turbine characteristics," Energy Conversion and Management, vol. 46, no.11, pp. 1848-1867, 2005

[21] Fagbenle R. O., Katende J., Ajayi O. O., and Okeniyi J. O. "Assessment of wind energy potential of two sites in North-East, Nigeria," Renewable Energy, vol. 36, no. 4, pp. 1277-1283, 2011.

[22] Data_source_google_earth. https://earth.google.com.

[23] PCBS, P. C. B. o. S.-. "Wind speed for gaza strip," Islamic University of Gaza, 2007.

[24] Worldwide Wind Speed Records http://climatevo.com.

\section{BIOGRAPHIES OF AUTHORS}

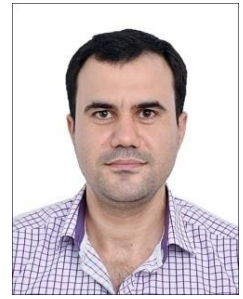

Ahmed Badawi, a PhD student in International Islamic University Malaysia (IIUM) from Malaysia. His study is about maximum power point tracking for small scale wind turbine under Electrical Engineering. Badawi have finished his Master degree in Wind Energy, Control Dept. (2013) Islamic University of Gaza, Gaza, Palestine. Subject: An Analytical Study for Establishment the Wind Farms in Palestine to Reach the Optimum Electrical Energy. Badawi has finished his B.Sc. Electrical Engineering Communication \& Control Dept. (08th June, 2010) from Islamic University of Gaza, Gaza, Palestine. His graduation project was based on pure sine wave ups using microcontroller. Awards and honors: badawi has been won the Award for Distinguished Graduation Research Projects and Master Dissertations for the year 2011-2012.he has many honors certifications, awards. Within his studying years. 

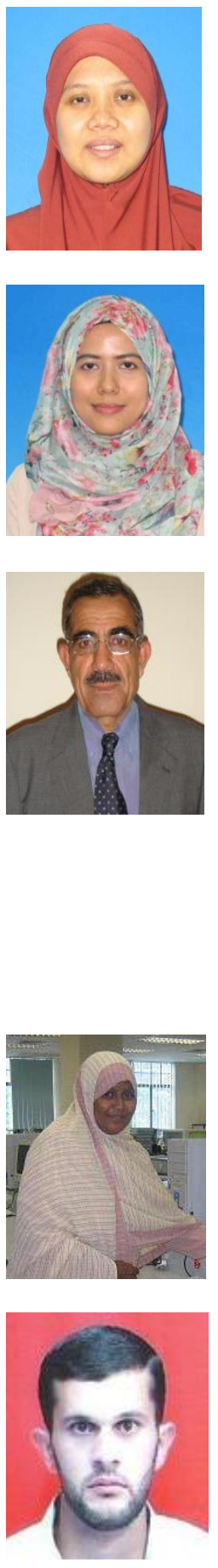

Alhareth Zyoud, had his bachelor degree in electrical engineering from polytechnic university in Palestine 2006. He got a master degree in communication engineering from international Islamic University Malaysia (IIUM) in 2011.then he also recieved a $\mathrm{PhD}$ from Electrical and Computer Engineering department at IIUM. His current research interests are in Interference cancellation, modeling and propagation studies in femtocells $4 \mathrm{G}$ and $5 \mathrm{G}$ networks. $\mathrm{He}$ is considered an active member of the IEEE.

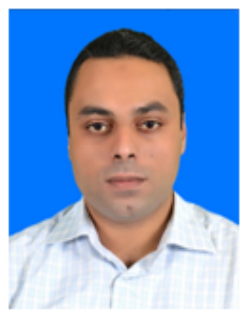

Mohammed Alamassie, a Teaching Assistant at Özyeğin Üniversitesi since Feb. 2015 he got a Bachelor Degree of Science in Electrical Engineering from The Islamic University of Gaza, Gaza-Strip, Palestine in Jan. 2006. He also received his master degree of Science in Electrical Engineering June 2011 from IUG. he also a Research/Teaching Assistant and Ph.D. candidateSince Feb. 2015 Özyeğin Üniversitesi, Çekmeköy, Istanbul, TURKEY. 